\section{IJ§ER}

ISSN: 2149-5939
International Journal of Social Sciences and Education Research

Online, http://dergipark.gov.tr/ijsser

Volume: 3(3), 2017

\title{
Bir yumuşak güç aracı olarak sinema: Hollywood örneği
}

Cinema as a soft power instrument: Hollywood cinema case

\author{
Burak Medin $^{1} \quad$ Serhan Koyuncu ${ }^{2}$
}

Received Date: 02 / 02 / $2017 \quad$ Accepted Date: 01 / $06 / 2017$

\begin{abstract}
$\ddot{O} z$
Fotoğraf, sinema, televizyon ve internet gibi iletişim teknolojilerinin gündelik yaşamımıza dâhil olmasıla, yaşamımız giderek imajlarla temsil edilmeye başlandı. Bu dijitalleşen imajlar, zamanla gerçeklerinden daha etkileyici ve algıları dönüştürücü bir işlev kazandl. Hatta inşa edilen bu imajlar, gerçeklerin yerini alarak gerçekliğin yeniden kurgulanmasında önemli görevler üstlendi. İmajların belli bir bağlam içinde tasarlandiğı ve dolaşıma sokularak bir meta ve güç unsuru olarak kullanıldiğı en önemli mecralardan biri olan sinema, zamanla ülkelerin diğer ülke ve kendi vatandaşlarıyla olan ilişkilerinde bir yumuşak güç aracı olarak etkin bir şekilde kullanılmaya başlandl. Kendi kültürünü ve ideolojisini hem kendi insanına hem de diğer ülke insanlarına sevdirme, hayranlık uyandırma ve gündem yaratma ve algıları yönlendirme konusunda sinemayı bir yumuşak güç unsuru olarak kullanan en önemli devletlerden biri ABD'dir. Amaçlı örneklem yöntemi bağlamında çeşitli filmleri ele alan bu çalışma ABD'nin, kamu diplomasisi faaliyetlerinde bir yumuşak güç unsuru olarak Hollywood sinemasını nasıl kullandığına, bellekleri ve algıları dönüşü̈rmeye yönelik imaj ve söylem yönetimine odaklanmaktadır.
\end{abstract}

Anahtar sözcükler: Yumuşak güç, Kamu Diplomasisi, Hollywood Sineması

\begin{abstract}
With the inclusion of communication technologies such as photography, cinema, television and the internet in our everyday lives, our lives have been increasingly being represented by images. These digitized images, over time, were more impressive than their realities and gained a perceptive transformative function. These images, even constructed, have taken on important tasks in reestablishing the reality by taking reality. The cinema, which is one of the most important media in which images are designed in a certain context and used as a commodity and power element by circulation, has gradually started to be used effectively as a soft power tool in the relations of the countries with the other country and its own citizens. One of the most important states that use cinema as a soft power element in favoring, cultivating, fostering an agenda and perceiving its own culture and ideology both to its own people and to the people of other countries is the United States. This study focuses on the management of images and discourse on how to use Hollywood cinema as a soft power element in public diplomacy activities, to transform memories and perceptions.
\end{abstract}

Keywords: Soft Power, Public Diplomacy, Hollywood Cinema

\section{Giriş}

Bu çalışmada ABD tarafindan Hollywood Sineması'nın bir yumuşak güç unsuru olarak nasıl kullanıldığına odaklanılmaktadır. Amaçlı örneklem yöntemiyle ele alınan filmler bağlamında küresel ölçekte önemli bir kitle sineması örneği olan Hollywood tarafından üretilen filmlerin Amerikan dış politikasındaki işlevi, uluslararası toplumlar üzerindeki değiştirici ve dönüştürücü etkisi ortaya konulmaya çalışılmaktadır. Bu bağlamda çalışmanın izlencesine yön verecek olan araştırma soruları aşağıdaki gibi formüle edilmiştir:

\footnotetext{
${ }^{1}$ Arş.Gör., Gazi Üniversitesi İletişim Fakültesi, Ankara/TÜRKIYY, burakmedin@hotmail.com

${ }^{2}$ Uzm., Gazi Üniversitesi İletişim Fakültesi, Ankara/TÜRKIYE, serhankoyuncu@hotmail.com
} 
Medin, B., Koyuncu, S. (2017). Cinema as a soft power instrument: Hollywood cinema case. International

Journal of Social Sciences and Education Research, 3(3), 836-844.

1- ABD’nin dış politikasındaki hedeflerine ulaşma noktasında Hollywood tarafından üretilen filmlerin işlevi nedir?

2- ABD'nin dış politikasını uygulaması hususunda bu filmler, uluslararası toplumu nasıl ikna etmekte ve şekillendirmektedir?

Çalışmanın ilk bölümünde güç kavramından hareketle yumuşak ve sert güç ayrımı yapılmış, kuramsal çerçeve bu şekilde inşa edilmiştir. İkinci bölümde ise yumuşak güç kavramından hareketle ABD'nin yumuşak gücünün bir enstrümanı olan Hollywood Sineması'ndan örnek filmler ideolojik bir perspektifle çözümlenmiştir.

\section{Güç kavramı ve yumuşak güç}

Gücün ne olduğu konusunda herkesin ortak bir görüşü olmasa da (Nye, 2004: 1), herkes ona bağımlı bir şekilde yaşar. Siyasi liderler de siyasi hayatları boyunca değişim ve dönüşüm içinde olan güç ilişkilerini anlamaya çalışırlar. Baldwin'in belirttiği gibi (1989: 59-70) güç kavramı sadece zorlamayı içermez. Diğer aktörlerin davranışlarının istenen şekilde yönlendirilebilmesi ve yönetilebilmesi için pozitif ve negatif yaptırımların uygulanabildiği bir olguyu ifade etmektedir. Bu pozitif ve negatif yaptırımlar arasında ise (Baldwin, 1989: 132-135; Waltz, 1967: 216) ironik bir ilişki söz konusudur.

Lukes (1974) gücün izlenebilir tarafı üzerinde yoğunlaşmakta ve birbiriyle ilintili davranışların neden sonuç ilişkileri ortaya çıkardığını belirtmektedir. Bu yaklaşım da güç, aktörler arasındaki ilişkiler yoluyla açıklanmaktadır. Bu nedenle davranışsal ya da ilişkisel yaklaşım olarak adlandırılmaktadır. Dahl'in tanımına göre (1957) güç, bir aktörün yapmayacağı şeyleri başka bir aktöre yaptırabilme kapasitesidir. A, B'nin üzerinde güç uygulayarak B'nin davranışını yönlendirmekte ve yönetmektedir. Bir aktörün davranışının nedeni olarak başka bir aktörü işaret eden bu yaklaşıma göre güç; bir aktörün sahip olduğu kaynaklar veya yeteneklere atıfta bulunur.

Her bir politika bağlamında gücün ayrı ayrı değerlendirilmesi gerektiğini ifade eden Baldwin'e göre (1984: 497), gücün kapsamını, bağlamını ve miktarını çözümleyebilmek için şu soru sorulmalıdır: "Kim, kime, hangi araçlarla, nerede, ne zaman ve hangi maliyetlere katlanarak, hangi başarı oranında, ne yaptırmaya çalışıyor?"

Uluslararası sistemin kontrolü neredeyse imkânsızdır. Belli bir konuda bir aktör diğeri üzerinde söz sahibi olabilir ama başka bir konuda bu kontrol ilişkisi tam tersi olabilir. Yani kontrol ve başkalarının davranışlarını değiştirebilme anlamında güç, aslında konuya ve bağlama göre değişebilen bir kavramdır. Bu bağlamdan hareketle Waltz (1979: 35, 191-192) gücü ne kaynaklar, ne de olaylar üzerinde kontrolün sağlanması olarak tanımlar. Bir süper gücü sistem içinde en güçlü aktör konumuna getiren her aktör üzerinde her konuda inşa ettiği kontrol ya da güç değildir. Eğer var olan sistem içinde o devlet en fazla hareket kabiliyetine sahipse o zaman süper güçten söz edebiliriz. Süper güçler çoğu zaman kendi müttefiklerinin bile davranışlarını kontrol edemez hale gelebilir. Bu doğrultuda Waltz, aktörlerin genellikle diğer aktörlerin davranışlarını istedikleri gibi yönlendirmesinin aslında mümkün olmadığına işaret eder. Waltz'a göre güç, karşllıklı bağımlılığa dayalı olan uluslararası sistemde diğer aktörlere en az bağımlı şekilde karar alabilme ve onların kararlarından da en az seviyede etkilenme kabiliyeti olarak tanımlanabilir. Güç, bir devletin birleştik yetenekleridir. Gücün başvurduğu yöntemler ile elde edilen sonuçları ayrı ayrı incelemek gerekir. Diğerlerini yönlendirebilmek gücün bir sonucudur. Güç, sürece etki edebilme 
Medin, B., Koyuncu, S. (2017). Bir yumuşak güç aracı olarak sinema: Hollywood örneği. International Journal of Social Sciences and Education Research, 3(3), 836-844.

kapasitesini ifade eder ve sistemin yapısı gereği sonuçlar belirsiz olabilir. Aktörlere sağlanan hareket serbestisi olarak açıklanabilen güç kavramının yanı sıra güç mücadelesi de başkaları üzerinde kontrol mücadelesi değil, sistem içerisinde mümkün olan en fazla hareket kabiliyetini kazanma mücadelesidir.

Sahip olunan ya da kontrol edilen kaynaklar ya da diğer aktörlerin davranışlarına etki etmek, Waltz'a göre gücün tanımı için sadece araçsal bir rol oynar; onu tanımlamaz. Kaynakları veya aktörleri kontrol altında tutan bir aktör istediği sonuçları elde etmek için onları kullanmıyor ya da zorlamıyorsa güçlü olduğu söylenemez. Öyleyse böyle bir kontrolü sağlamak için diğer dinamiklerin de dikkate alınması gerekir. Bu bağlamda bu çalışmanın ana eksenlerinden bir olan yumuşak güç kavramını açıklamaya başlayabiliriz.

Joseph S. Nye tarafından (Nye, 2005: 7-9) literatüre kazandırılan bir kavram olan yumuşak güç, ilk kez 1990 yılında yayımlanan Bound to Lead adlı kitapta ele alınmıştır. Nye'a göre yumuşak güç başkalarının tercihlerini şekillendirme, değiştirme ve dönüştürme becerisidir. Sert güçte olduğu gibi zorlama ya da baskı, yumuşak güçte söz konusu değildir. Burada başat olan karş1 tarafı yanına çekmektir. Yumuşak güç ile nüfuz etme birbirine karıştırılmaması gereken kavramlardır. Nüfuz etme tehdit ve paranın sert gücüne dayanır. Yumuşak gücün temeli ise kendine çekme becerisine ve bu çekiciliğe dayanmaktadır. Nye'nın deyişiyle (2005: 15-17) yumuşak ve sert güç birbiriyle ilişkilidir. Gücün farklı yönlerine vurgu yapan bu kavramlar başkalarının davranışlarını etkileyerek amaca ulaşma becerisinin farklı kollarını oluştururlar. Yumuşak güç ve sert güç arasındaki temel fark hem davranışların niteliğinde hem de kaynakların somutluğundadır. Sert güç kaynakları genellikle emir davranışıyla ilişkiliyken yumuşak güç kaynakları ise davranış spektrumunun "kendine çekme" ucuyla birleşmektedir. Yumuşak gücün temelinde sert güçte olduğu gibi etki etme yoktur. Sert güç ile yumuşak güç arasındaki fark elde edilmek istenen sonuca ulaşmada izlenen yoldur. Ancak ikisinde de ulaşılmak istenen bir amaç söz konusudur ve bu açıdan benzerlik taşırlar. Bu iki kavramı aşağıdaki tablodan hareketle daha iyi açıklayabiliriz.

Tablo 1. Sert ve Yumuşak Güç

\begin{tabular}{|l|l|l|}
\hline & Sert Güç & Yumuşak Güç \\
\hline Davranış Spektrumu & $\begin{array}{l}\text { Emir } \\
\text { Zorlama }\end{array}$ & $\begin{array}{l}\text { Gündem belirleme } \\
\text { Cazibe } \\
\text { Seçim }\end{array}$ \\
\hline Kaynaklar & Yaptırım & $\begin{array}{l}\text { Kurumlar, dernekler } \\
\text { Değerler } \\
\text { Kültür } \\
\text { Politika }\end{array}$ \\
& Maddi Ödeme & \\
& & \\
\hline
\end{tabular}

Kaynak: Nye, 2004: 8

Tablo 2. Güç Formları

\begin{tabular}{|l|l|l|l|}
\hline Güç Boyutları & Davranışlar & Temel Araçlar & Hükümet Politikaları \\
\hline Askeri Güç & $\begin{array}{l}\text { Zorlama, } \\
\text { Caydırma } \\
\text { Koruma }\end{array}$ & $\begin{array}{l}\text { Tehdit } \\
\text { Kuvvet }\end{array}$ & $\begin{array}{l}\text { Zorlayıcı Diplomasi } \\
\text { Savaş } \\
\text { İttifak }\end{array}$ \\
\hline Ekonomik Güç & $\begin{array}{l}\text { Teşvik } \\
\text { Zorlama }\end{array}$ & $\begin{array}{l}\text { Para verme } \\
\text { Yatırım }\end{array}$ & $\begin{array}{l}\text { Yardım } \\
\text { Rüşvet }\end{array}$ \\
\hline Yumuşak Güç & Hayranlık uyandırma & $\begin{array}{l}\text { Değerler } \\
\text { Kültür }\end{array}$ & $\begin{array}{l}\text { Kamu diplomasisi } \\
\text { Güki taraflı ve çok taraflı } \\
\text { demokrasi }\end{array}$ \\
& Goündem yaratma & Kurumlar & \\
\hline
\end{tabular}

Kaynak: Nye, 2005: 37 
Medin, B., Koyuncu, S. (2017). Cinema as a soft power instrument: Hollywood cinema case. International

Journal of Social Sciences and Education Research, 3(3), 836-844.

Askeri ve ekonomik unsurları içeren sert güç kullanımıyla ülkelerin ikna edilmesi ve yönlendirilmesi mümkündür. Fakat ülkelerin yönlendirilmesi, algılarının değiştirilmesi ve dönüştürülmesi, uluslararası ortamın ulaşılmak istenen hedefler bağlamında şekillendirilmesi sert güç unsurlarına başvurmadan da mümkündür. Bu güç yukarıda ifade ettiğimiz gibi yumuşak güçtür. Yumuşak gücün temelinde zorlama, baskı ya da tahakküm yoktur; cazibe ve çekicilik vardır. Diğerlerinin tercihlerinin şekillenmesinde önemli bir işleve sahiptir.

Hem daha düşük maliyetli ve daha kalıcı sonuçlar doğurabilen hem de aynı zamanda meşruiyet ve rıza unsuru içeren yumuşak güç yöntemleri (Mor, 2006) uluslararası politikada en etkin güç kullanımı olarak karşımıza çıkmaktadır. Gücün etkin kullanımı ancak ona meşruiyet kaynakları yaratarak mümkün olabilir. Bilgi ve iletişim teknolojilerindeki hızlı gelişmelerle imajların daha önemli hale gelmesi, güç politikalarının belli düzeyde meşruiyete dayandırılma mecburiyetini ortaya çıkarmıştır. Bu hem uluslararası politikanın doğası gereği hem de artık yaygınlaşan ve güçlenen uluslararası örgütler, küresel medya ve uluslararası hukukun gereğidir. Yürütülecek her politika, uluslararası kamuoyuna meşru bir açıklama ile birlikte sunulmalıdır; aksi halde arzulanan hedeflere ulaşmak imkânsız hale gelebilir. Yumuşak güç kullanımı için gerekli olan çekicilik unsuru; meşruiyet, inandırıcılık ve saygınlıktır.

Yumuşak gücün kaynaklarına bakıldığında birçok unsurla karşılaşırız: Müzik, insanların yaşayış biçimleri, yeme içme alışkanlıkları, dil, eğitim, siyasi değerler, diziler vs. Sinema ise çok kısa bir süre içinde geniş bir kitleye ulaşması bağlamında belki de en etkili yumuşak güç unsurlarının başında gelmektedir. Algıları şekillendirmek ve bellekleri arzulanan politik hedeflere ulaşmak amacıyla dönüştürmek için günümüzde sinema uluslararası aktörler tarafından sıklıkla kullanılmaktadır. Potansiyel olarak birçok yumuşak güç sağlayıcısı konumunda olan ABD'nin belki de en etkili enstrümanı Hollywood Sineması'dır. Amerikan sinema film endüstrisi olan Hollywood, sinema sektöründe egemen konumda olup tüm dünyaya ulaşmakta, algıları ve düşünce yapılarını etkilemektedir.

$\mathrm{Bu}$ çalışmada da uluslararası arenada bir süper güç konumunda olan ABD'nin bir yumuşak güç unsuru olarak Hollywood Sineması'nı nasıl kullandığına, kendi meşruiyetini, inandırıcılı̆̆ını ve saygınlığını nasıl inşa ettiğine odaklanılmakta filmler üzerinden okumalar yapılmaktadır.

\section{Bir yumuşak güç unsuru olarak Hollywood Sineması'nın kullanımı}

Film okumalarına Argo (2012) filmiyle başlayabiliriz. 85. Oscar ödül töreninde 7 dalda aday olan Argo, 3 dalda ödül kazanırken akademi tarafından en iyi film seçildi. Film Şah'ın devrilmesinin ardından Tahran'daki ABD Büyükelçiliğgi'nin basılıp 52 ABD'li diplomatın rehin alınmasını, diplomatlardan 6 tanesinin büyükelçilik binasından kaçmasını ve CIA'nin bu diplomatları Tahran'dan çıkarma girişimini konu ediniyor. Ödül töreninde filmin yönetmeni Ben Affleck "şu anda korkunç şartlar altında yaşayan İran'daki dostlarımıza teşekkür etmek istiyorum" diyerek esasında filmini hangi ideoloji üzerine oturttuğunu açıç̧a gözler önüne sermektedir. Dahası Argo filminin en iyi film ödülünü kazandığını Michelle Obama, Beyaz Saray’dan bağlanarak duyurur. Böylece sadece bu iki kesit bile ABD ile Hollywood arasındaki yakın ilişkiyi gözler önüne sermeye yeter. ABD yönetiminin menfaatleri doğrultusunda politik ve askeri hedeflerini meşru kılacak filmlere olan desteği açık bir şekilde ifşa olmuştur. Argo filminin vizyona girdiği ve ödül aldığı zaman diliminde İran'a karşı olası bir askeri müdahale konuşulmakta, uluslararası kamuoyunun dikkati İran'ın üzerine çekilmeye çalışılmaktaydı. 
Medin, B., Koyuncu, S. (2017). Bir yumuşak güç aracı olarak sinema: Hollywood örneği. International Journal of Social Sciences and Education Research, 3(3), 836-844.

Yüzeysel okumada karşımıza ilk etapta bunlar çıkar. Filmin kesitlerine baktığımızda ise yine oryantalist söylemlerle karşı karşıya kalırız. İranlılar yağmacı, çirkin, fanatik, etraftaki her şeyi yakan ve yıkan, aşırı dinci, hiç çekinmeden terör estiren, gerektiğinde hiç acımadan linç edebilen, cahil, kaba-saba insan dışı varlıklar olarak takdim edilir. İnsanların bu karanlık görüntülerine sarık ve tespih gibi islam dinine ait simgeler de eklenir. İran ise bir cehennem, insanların kurtarılması gereken distopik bir mekan olarak gösterilir. Sinematografik dil de bu ideolojiyi destekler niteliktedir. Filmin gerçekçiliğini arttırmak üzere aktüel kamerayla çekilmiş imajı uyandıran sallantılı görüntüler kullanılır. Buradaki amaç sanki arşiv görüntülerinden yararlanılıyormuş algısı yaratılarak gerçekçiliği arttırmaktır. İzleyicide sanki belgesel izliyormuş hissi yaratılmaya çalışılmıştır. Gerçeklik ise filmde belli bir ideoloji bağlamında yeniden inşa edilmektedir.

İran Kültür Bakanı Muhammed Hüseyni Argo filminden hareketle şu yorumu yapar: Hollywood tarihi çarpıttyor. Bu film, Irran'a karşı verilen yumuşak güç savaşının parçasıdır. Görüldüğü üzere ABD dış politikası ve film üretiminde ciddi bir paralellik söz konusudur. İran müdahale edilmesi, insanların içinde bulundukları bu kötü durumdan bir an evvel kurtarılması gereken bir distopya olarak belleklere kazınmaktadır. Böylece uluslararası toplum, İran'a karşı yapılan herhangi bir müdahaleye rıza gösterir hale gelebilecektir.

2012 yapımı bir diğer film olan Lincoln'de ABD'nin eski başkanlarından olan Abraham Lincoln'ün köleliği ortadan kaldıran bir kanunu geçirme çabaları anlatılıyor. $\mathrm{ABD}$, neredeyse tüm klasik anlatı sineması filmlerinde olduğu gibi yine özgürlük ve demokrasi adına mücadele eden taraf olarak izleyicinin karşısına çıkıyor. Özgürlük ve demokrasi adına mücadele eden ABD başkanı Lincoln'den hareketle, ABD'nin özgürlüğün ve demokrasinin merkezi ve savunucusu olduğu algısı oluşturulmaya çalış1lıyor. ABD'nin Ortadoğu üzerine gerçekleştirdikleri eylemlerdeki temel argümanı çoğunlukla özgürlük ve demokrasi olmuştur. Bu film anlatıları bu tarz dış politikaların uygulanması noktasında hem ABD halkının hem de diğer toplumların ikna edilmesinde ve bu operasyonların meşruiyetini sağlaması bakımından son derece önemli bir rol oynamaktadır.

Hollywood Sineması'nda Araplarla ilgili kurmaca anlatılar sıklıkla üretilmiştir. Fakat Arapların Amerikan Sineması'nda yer alması genellikle Batı'nın Doğu üzerinden ürettiği oryantalist söylem bağlamında olmuştur. Örneğin bu türün klasiklerinden biri olan Beau Geste (1926) adlı filmde İngiliz ve Fransız birlikler Araplarla savaşmaktadır. Bu filmin kesitlerinde görülen sahne genellikle atlar üzerindeki Arapların sayıları az olan ve olumsuz koşullarda varlığını devam ettiren yabancı askeri birliklere saldırmalarıdır. Bu tarz anlatılarda at üzerinde radikal islamcılar olarak gösterilen Arapların çoğunlukla herhangi bir kimliği yoktur. İsimleri ve yüzleri olmayan bu insanlara karşı Batılı, bu filmler üzerinden her zaman galibiyetini ilan etmektedir. Bu bakış açısına sahip olan anlatılardaki hakim ideoloji sömüren tarafın göz ardı edilmesi, sömürülen tarafın ise distopik öğelerle betimlenerek işgaline uluslararası kamuoyunda meşruluk kazandırılmasidır.

Mumya filmlerinde de (The Mummy-1932, The Mummy's Hand-1940, The Mummy 1959, Tale of The Mummy-1998, The Mummy 1999, The Mummy Returns-2001, The Mummy: Tomb of the Dragon Emperor-2008) oryantalist söyleme dayanan bir anlatı devrededir. Bu film anlatılarında Avrupalı ve Mısırlı erkek arasındaki kavga izleyiciye sunulur. Avrupalı ya da Amerikalı beyaz erkek arkeologtur ve aklı, çağdaşlığı, temizliği, barışı ve özgürlüğü temsil eder. Mısırlı insanlar ise yine akılsız, pis, radikal ve yağmacı olarak betimlenir. İyi olan beyaz Avrupalı ya da Amerikalı erkeğe karşın yüzyıllar evvel mumyalanmış kötücül, lanetlenmiş bir Mısır'lıyla karşılaşırız. Doğu despotizmi ve çürümüşlüğü bilimle, özgürlükle, gençlikle, hayatla, demokrasiyle çatışma halinde 
Medin, B., Koyuncu, S. (2017). Cinema as a soft power instrument: Hollywood cinema case. International

Journal of Social Sciences and Education Research, 3(3), 836-844.

sunulur. Bu ikili karşıtlık nihayetinde Batılıların Mısırlıları alt etmesi ve buralara özgürlük ve huzur getirmesiyle nihayete erer.

Olympus Has Fallen (2013) adlı filmde ise Kuzey Koreli teröristlerin Beyaz Saray'1 gizli bir operasyonla ele geçirerek Amerikan başkanını rehin almaları anlatılır. Filmden hareketle Kuzey Kore'nin Asya kıtasındaki en büyük düşman ilan edildiği görülmektedir. Kuzey Kore bir yandan Güney Kore'yi tehdit etmekte, bir yandan da nükleer füze denemelerine ara vermeksizin devam etmektedir. Uluslararası barışı tehdit eden bir ülke olarak izleyiciye sunulan Kuzey Kore, günümüzde de aynı suçlarla itham edilmekte, Kuzey Kore lideri faşist bir diktatör gibi ekranlarda yer almaktadır. ABD Başkanı Trump ise demeçlerinde Kuzey Kore'nin dünyayı savaşa sürüklediğini her firsatta dile getirmekte, bu coğrafyaya özgürlük getireceğine dair çeşitli ifadeler kullanmaktadır. Filmde ayrıca ABD'de oluşabilecek bir yönetim boşluğunun tüm dünyada bir kaosa neden olabileceğinin de altı çizilmektedir. Bu nedenle ABD'nin dünyadaki lider ülke konumunun sürdürülmesi gerektiği zihinlere pompalanmaktadır. Üzerinde önemle durulması gereken noktalardan biri de Beyaz Saray'a gerçekleştirilen saldırının ve Başkanın rehin alınmasının Ortadoğu halkları tarafından sevinçle karşılandığı görüntülerdir. Bu görüntüler üzerinden hem Asya' daki hem de Ortadoğu'daki bazı ülkeler açıkça düşman ilan edilmektedir.

\section{Sonuç}

ABD diş politikadaki hedeflerine ulaşmak amacıyla birçok araçtan yararlanmakta, bir yumuşak güç unsuru olarak ise Hollywood Sineması'nı etkin bir şekilde kullanmaktadır. ABD, küresel bağlamda film endüstrisine hâkim olan Hollywood Sineması aracılığıyla kendi halkının özellikle de diğer toplumların inanç ve fikir dünyalarını, sosyo-kültürel ve ekonomik yapılarını biçimlendirmekte ve ehlileştirmektedir. Bu endüstri tarafından üretilen film anlatıları, ABD'nin dış politik amaçlarına daha rahat ve kolay ulaşabilmesine, ayrıca dış politikadaki edimlerini daha rahat gerçekleştirebileceği uluslararası bir ortamın inşasına katkı sağlamaktadır.

Araştırma nesnesi konumunda olan film anlatıları göstermiştir ki Hollywood Sineması, ABD’nin uluslararası arenadaki politik amaçlarını rahatlıkla gerçekleştirebilmesinde önemli bir eyleyen konumundadır. ABD ideolojisi bağlamında üretilen bu filmler hem iç hem de dış ortamı, ABD'nin gerçekleştireceği eylemler konusunda hazırlamaktadır. Toplumların iletişimsel bellekleri filmler dolayımından geçirilerek ABD'nin yapacağı eylemlerin meşruiyetine hazırlanmakta, bu ülkenin yapacağı herhangi bir eylemin haklı bir gerekçe üzerine oturduğuna ikna edilmektedir. Uluslararası kamuoyu bu politik tasarrufların gerekliliğine ya da neden yapıldığına film anlatılarının ideolojik yapısı bağlamında rıza gösterir hale getirilmektedir.

Etkili bir yumuşak güç konumunda olan Hollywood filmleri ABD'nin dış politikasını ve bu politika bağlamında üretilecek operasyonel eylemlerin rahat bir şekilde uygulanmasını kolaylaştırmanın yanı sıra bu film anlatıları aynı zamanda Amerikan yaşam tarzının, müziklerinin, eğitim yapısının, geleneklerinin, mimari yapılarının, inanç yapısının ve tüm bunlarla ilintili birçok kültür unsurunun diğer toplumlara aktarılmasında önemli bir rol üstlenmektedir.

\section{Kaynakça}

Baldwin, D. A. (1984). Interdependence and Power: A Conceptual Analysis, International Organization, 34/4: 471-506.

Baldwin, D. A. (1989). Paradoxes of Power. New York: Basil Blackwell.

DAHL, R. (1957). The Concept of Power, Behavioral Sciences, vol. 2: 201-215. 
Medin, B., Koyuncu, S. (2017). Bir yumuşak güç aracı olarak sinema: Hollywood örneği. International Journal of Social Sciences and Education Research, 3(3), 836-844.

Lukes, S. (1974). Power: A Radical View. London: MacMillan Press.

MOR, B. D. (2006). Public Diplomacy in Grand Strategy, Foreign Policy Analysis, 2/2: 157-176.

Nye, J. (2004). Soft Power - The Means To Success in World Politics. New York: Public Affairs.

Nye, J. S. (2005). Dünya siyasetinde başarının yolu - yumuşak güç. Ankara: Elips Yayınları.

Nye, J. (2005). Yumuşak güç. Ankara: Elips Kitap.

Waltz, K. (1967). International Structure, National Force, and the Balance of World Power, Journal of International Affairs, 21/2: 215-231.

Waltz, K. (1979). Theory of International Relations. New York: McGraw Hill. 
Medin, B., Koyuncu, S. (2017). Cinema as a soft power instrument: Hollywood cinema case. International

Journal of Social Sciences and Education Research, 3(3), 836-844.

\section{Extended abstract in English}

This study focuses on how Hollywood Cinema is used as a soft power element by the USA. In the context of films covered by purposeful sampling, the role of films produced by Hollywood, which is an example of an important mass cinema on a global scale, is being tried to put forward the changing and transformative effect of American foreign policy on international societies.

In this context, the research questions that will guide the accuracy of the study are formulated as follows.

1- What is the function of films produced by Hollywood at the point of reaching its foreign policy goals?

2. How are these films convincing and shaping the international community to apply USA foreign policy?

In the first part of the work, soft and hard power is separated from the power concept and the theoretical framework is constructed in this way. In the second part, the sample films from Hollywood Cinema, an instrument of the soft power of the United States, based on the concept of soft power, were analyzed with an ideological perspective.

Soft power, a concept conferred by the literature by Joseph S. Nye, was first described in the book Bound to Lead, published in 1990. According to Nye, soft power is the skill of shaping, changing and transforming the preferences of others. Forcing or pressure, like hard power, is not a matter of soft power. Here is the main thing to attract the other side. Soft power and penetration are concepts that should not be confused with each other. Penetration is a threat and depends on the hard power of money. The basis of soft power is based on self-attraction and this attraction. In the words of Nye, soft and hard power are related. These concepts, which emphasize the different aspects of the power, constitute the different branches of achieving ability by influencing the behavior of others. The main difference between soft power and hard power is both in the nature of behavior and in the materiality of resources. Hard power sources are often associated with order behavior, while soft power sources are associated with the "pulling" end of the behavioral spectrum. There is no effect on the basis of soft power as it is hard power. The difference between hard power and soft power is the way to get to the desired result. However, both have an aim to be reached, and in this respect they carry a similarity.

Both soft power methods that can result in lower cost and more permanent results and at the same time legitimacy and consent appear to be the most effective use of power in international politics. Effective use of power can only be possible by creating legitimacy. Rapid developments in information and communication technologies have made images more important, necessitating a certain degree of legitimacy of power politics. This is both the nature of international politics and the need for international organizations, global media and international law, which are now becoming more widespread and empowering. Any policy that is to be implemented must be accompanied by a legitimate explanation to the international public; Otherwise it may become impossible to achieve the desired goals. The charm element required for the use of soft power; Legitimacy, credibility and respectability.

When we look at the sources of soft power, we encounter many elements: music, people's lifestyles, eating habits, language, education, political values, Cinema is perhaps one of the most effective soft power elements in terms of reaching a wide audience in a very short time. Today, 
Medin, B., Koyuncu, S. (2017). Bir yumuşak güç aracı olarak sinema: Hollywood örneği. International Journal of Social Sciences and Education Research, 3(3), 836-844.

cinema is often used by international actors to transform perceptions and shape memory to achieve the desired political goals. Perhaps the most effective instrument of the USA, which is potentially the most mild power supplier, is Hollywood Cinema. Hollywood, the American film industry, dominates the cinema industry and reaches the whole world, influencing perceptions and thoughts.

This study also focuses on how the USA, which is a superpower in the international arena, uses Hollywood cinema as a soft power element and how to construct its own legitimacy, credibility and respectability.

As a result, the USA takes advantage of many tools to achieve its foreign policy goals, and effectively uses Hollywood Cinema as a soft power element. Through the Hollywood movie, which dominates the film industry in a global context, the United States shapes its people, especially the sociocultural and economic structures of beliefs and ideas of other societies. This industry-generated film commentary contributes to the construction of an international environment in which the United States can reach its foreign policy goals more easily and easily, and can more easily fulfill its foreign policy actions.

The research on the object of the film showed that Hollywood Cinema is an important actor that can make the international political goals of the United States easier. These films, produced in the context of US ideology, prepare both internal and external environment for actions that the United States will take. The communicative memories of the societies are being passed through films to prepare for the legitimacy of the actions the United States will take, and it is convinced that any action that this country will take is justified. The international public has been made conscientious in the context of the ideological nature of the film's narratives, whether or not these political savings are necessary.

The Hollywood movies, which are in an effective soft power position, facilitate the smooth implementation of USA foreign policy and operational actions in the context of this policy, as well as the American lifestyle, music, education structure, traditions, architectural structures, It plays an important role in transferring many cultural elements related to these to other societies. 